\title{
Higher dietary diversity as a protective factor against depression among older adults in China: a cross-sectional study
}

\author{
Rong Li ${ }^{1 \# \wedge}$, Zhi-Ying Zong ${ }^{1 \#}$, Xi-Xi Gu ${ }^{1 \#}$, Dan-Ni Wang ${ }^{1}$, Chen Dong ${ }^{1}$, Chi Sun ${ }^{2}$, Rui Zhao \\ Zhi-Feng Gu ${ }^{3}$, Jian-Lin Gao
}

${ }^{1}$ Research Center of Gerontology and Longevity, Research Center of Clinical Medicine, Affiliated Hospital of Nantong University, Nantong, China; ${ }^{2}$ Department of Geriatrics, Affiliated Hospital of Nantong University, Nantong, China; ${ }^{3}$ Department of Rheumatology, Affiliated Hospital of Nantong University, Nantong, China

Contributions: (I) Conception and design: R Li, ZY Zong; (II) Administrative support: ZF Gu, JL Gao; (III) Provision of study materials or patients: All authors; (IV) Collection and assembly of data: R Li, ZY Zong, DN Wang, R Zhao, C Dong, C Sun; (V) Data analysis and interpretation: R Li, ZY Zong, XX Gu; (VI) Manuscript writing: All authors; (VII) Final approval of manuscript: All authors.

\#These authors contributed equally to this work.

Correspondence to: Jian-Lin Gao. Research Center of Gerontology and Longevity, Affiliated Hospital of Nantong University, Xisi Road 20\#, Nantong 226001, China. Email: JL4486@ntu.edu.cn; Zhi-Feng Gu, PhD. Department of Rheumatology, Affiliated Hospital of Nantong University, Xisi Road 20\#, Nantong 226001, China. Email: guzf@ntu.edu.cn.

Background Evidence suggests that poor mental health $(\mathrm{MH})$ is a risk factor for the health of older adults. Dietary diversity is considered to be related to healthy aging. However, the relationship between diet and $\mathrm{MH}$ is still unclear. Therefore, the purpose of this study was to investigate the relationship between dietary diversity score (DDS) and anxiety and depression among centenarians and their offspring and spouses.

Methods: Our study was observational and cross-sectional. The Generalized Anxiety Disorder Scale (GAD7), the 15-item version of the Geriatric Depression Scale (GDS-15), and the dietary frequency questionnaire were used to measure the status of anxiety, depression, and dietary diversity. Data were analyzed by Student's $t$-test, $\chi^{2}$ test, Mann-Whitney $\mathrm{U}$ test, correlational analysis, and univariate or multivariate logistic regression. Results: Among the 288 older adults, 12.8\% reported symptoms of depression, and 8.7\% reported anxiety. People with a lower dietary diversity had higher rates of anxiety and depression. After controlling for age, place of residence, economic status, alcohol drinking, and physical activity, a lower DDS was found to be a risk factor for depressive symptoms [odds ratio (OR): 2.237; 95\% confidence interval (CI): 1.009-4.959; $\mathrm{P}=0.048$. DDS was negatively correlated with depression score in older adults $(\mathrm{r}=-0.224 ; \mathrm{P}<0.001)$, especially offspring and their spouses $(\mathrm{r}=-0.275 ; \mathrm{P}<0.001)$. However, no significant relationship was observed between DDS and anxiety. In addition, eating legumes (OR: 0.415; 95\% CI: 0.188-0.920; P=0.030) and nuts (OR: 0.255; 95\% CI: 0.116-0.561; P=0.001) at least once a week can act as protective factors for depression. Eating nuts (OR: 0.405; 95\% CI: 0.168-0.978; P=0.044) and meat (OR: 0.396, 95\% CI: 0.161-0.975; $\mathrm{P}=0.044$ ) at least once a week can act as protective factors for anxiety.

Conclusions: These results suggest an association between low dietary diversity and a higher incidence of mental disorders. Further, the possibility of reverse causality cannot be ruled out. It is necessary to conduct further prospective studies.

Keywords: Depression; anxiety; dietary diversity; elderly; older adults

Submitted May 31, 2021. Accepted for publication Oct 14, 2021.

doi: 10.21037/apm-21-1449

View this article at: https://dx.doi.org/10.21037/apm-21-1449

$\wedge$ ORCID: 0000-0001-6132-164X.

(c) Annals of Palliative Medicine. All rights reserved. 


\section{Introduction}

With the progressive aging of the population and the extension of people's life expectancy, the number of people aging into exceptional longevity is rapidly expanding worldwide (1). At the same time, anxiety and depression have become the most common mental health $(\mathrm{MH})$ problems among older adults (2). According to the World Health Organization (WHO), approximately $20 \%$ of older adults aged $\geq 60$ years old have varying degrees of depressive symptoms (3). Even beyond diagnosed conditions, subclinical symptoms of depression and anxiety also severely limit psychosocial functioning, not only diminishing quality of life but also impairing cognitive function, reducing wellbeing, and, in extreme cases, precipitating suicide $(4,5)$. The $\mathrm{MH}$ issues incur a massive burden on individuals, families, and national health services (6). The common branch between longevity health sciences (LHS) and MH consists of personal sanogenesis at an individual level and public health at the societal level (7). There is evidence that the $\mathrm{MH}$ of people older than 95 years is a significant predictor of longevity (8). Thus, depression and anxiety among older adults cannot be ignored, and how to maintain $\mathrm{MH}$ has become a challenge for China in achieving the Healthy 2050 plan (9).

In recent years, there has been considerable interest in the relationship between diet and MH. The field of nutritional psychiatry (10) is a rapidly growing one, and in fact, epidemiological studies have shown that adherence to a healthy dietary patterns, such as the Mediterranean diet (MED) and vegetarian diet, can reduce the risk of depression (11-13). In addition, studies of new interventions to implement dietary changes show promise in preventing and treating depression (14). However, most of these dietary patterns were developed based on data from Western populations, and some food groups included in these patterns are consumed differently among Chinese people in terms of quantity and the cooking methods used (15). Thus, the applicability of these patterns in Chinese populations remains unclear. Dietary diversity score (DDS), which has been universally recognized as a critical element of highquality diets, is recommended in dietary guidelines $(16,17)$. There is evidence that dietary diversity is an essential determinant of health and survival, especially in the aged $(18,19)$. Its simple scoring method can be applied to a wide range of different populations and all age groups. People, especially older adults, can understand DDS without having to consult a nutritionist. Given the enormous burden of mental disorders, the relationship between dietary diversity and anxiety and depression needs to be clarified so that a basis for formulating dietary intervention measures can be constructed. Indeed, even small improvements in diet can be of great benefit to the $\mathrm{MH}$ and well-being of aging individuals (20).

However, as far as we know, no study has examined the relationship between dietary diversity and $\mathrm{MH}$ in Chinese older adults, particularly centenarians, and thus the relationship between their eating habits and the $\mathrm{MH}$ of this population is still unclear. In the present study, our primary objectives were to (I) investigate the prevalence of depression and anxiety symptoms in an older adult population and (II) explore the relationship between dietary diversity and the probable disorders of depression and anxiety. We present the following article in accordance with the STROBE reporting checklist (available at https://apm. amegroups.com/article/view/10.21037/apm-21-1449/rc).

\section{Methods}

\section{Study design and participants}

The distribution of longevity population is geographically clustered. The United Nations standard for assessing the "Longevity region" is that there should be more than 75 centenarians per million people $(21,22)$. The ratio of centenarians in Rugao reached 36.9 per 100,000 people. Our research region of Rugao was voted "China's longevity region" and "the world's longevity region" in 2008 and 2011 (21). We implemented a cross-sectional study of older adults in Rugao, Jiangsu province from May to August 2020.Through the government's help, we attempted to identify the centenarians living there and included them in the study. We also surveyed their offspring and spouses who lived with them. The subjects were invited to participate in the study if they met the following eligibility criteria: (I) be able to communicate, (II) centenarians are required to be over 100 years old, which means the date of birth on the ID card is earlier than December 31, 1921 and (III) the offspring/spouse group must be over 60 years old. The exclusion criteria were: (I) serious physical illness resulting in any special diet, (II) inability to understand the question and (III) not finishing the questionnaire. The study was conducted in accordance with the Declaration of Helsinki (as revised in 2013). The study protocol and the consent form were approved by the Ethics Committee of The Affiliated Hospital of Nantong University and written informed 
consent was obtained from all participants. The Clinical Trial Registration number for this study is 2019-K045.

\section{Assessment of dietary diversity}

The DDS was used as an indicator of diet quality based on previous studies in Bangladesh that have linked DDS to dietary nutrient intakes (23). Based on the Food and Agriculture Organization of the United Nations (FAO) [2013] guidelines, we measured DDS through the use of questionnaires. We investigated the frequency of consumption of 9 food types through face-to-face interviews, including vegetables, fruits, legumes, and their products, nuts, meat, eggs, fish, dairy and its products, and tea. We asked participants how often they ate one of the above, giving 1 point if they answered at least once a week and giving no points otherwise. Each food was scored, and the scores were added together into a final score that could range from 0 to 9 , with higher scores indicating better dietary diversity. According to the suggestions of FAO and the method used in Yin et al.'s (24) research, DDS was divided into a low group and a high group, as determined by the mean value.

\section{Assessment of anxiety and depression}

The Generalized Anxiety Disorder Scale (GAD-7) (25) is a 1-dimensional instrument designed to detect anxiety that has been validated in the general population (26). The item scores range from 0 (not at all) to 3 (nearly every day); therefore, GAD-7 scores range from 0 to 21 , with scores of $\geq 5, \geq 10$, and $\geq 15$ represent mild, moderate, and severe anxiety symptom levels respectively (25). Our study considered scores between 0 and 4 to represent normal and those between 5 and 21 to represent abnormal. The 15 -item version of the Geriatric Depression Scale (GDS-15) (27) was used to detect depression, and it has been validated in a community sample of individuals over 85 years of age (28). Participants were asked to answer yes or no to each item based on how they felt over the past 2 weeks on a scale of 0 to 15 . The totaled GDS scores were classified as follows: $0-4=$ normal and $5-15=$ depression (29).

\section{Covariate assessment}

Data on age, gender, smoking, alcohol drinking, place of residence, degree of education, marital status, employment status, economic conditions, physical exercise, a history of chronic diseases (including hypertension, diabetes, and stroke), and body mass index (BMI) were obtained by a selfadministered questionnaire. The Barthel Index (BI) was used to evaluate the level of dependence of an individual in 10 instrumental activities of daily living. Lower scores indicated poorer physical function (30).

\section{Statistical analysis}

Statistical analysis for this study was performed using SPSS software (version 21). A total of 288 individuals were divided into 2 groups, centenarians ( $\geq 100$ years old) and their offspring and spouses ( $<100$ years old). Normally distributed data, assessed by a Kolmogorov-Smirnov test of normality, were presented as mean values with standard deviation (SD); non-normally distributed data were presented as medians with interquartile range (IQR). Categorical variables were expressed as numbers (percentage). Participants' psychological status (normal or abnormal) was compared by $t$-test or Mann-Whitney $\mathrm{U}$ for continuous variables and by chi-square test for categorical variables. Binary logistic regression was used to analyze the odds ratio (OR) and $95 \%$ confidence intervals (CIs) of low DDS to explore the associations of DDS with anxiety and depression, for which the anxiety and depression status were each used as dependent variables. We also assessed the relative contributions of the 9 food groups included in DDS concerning anxiety and depression. A $\mathrm{P}$ value $<0.05$ was considered to be statistically significant.

\section{Results}

\section{Sociodemographic characteristics of the sample}

In total, 288 individuals, including 38 (13.19\%) centenarians, were analyzed in this research, and their basic characteristics are described in Table 1 . The median age of all the participants was 72 [68-79] years old, with a BMI of $24.37 \pm 3.90$. The median age of the centenarian group was 101 [100-102] years old, and the oldest was 110 years old. BI reflected the good physical function of this older adult group, with $84 \%$ being judged as an independent. The prevalence of depression and anxiety symptoms was $12.8 \%$ and $8.7 \%$, respectively, among the older adults. However, in the centenarians, the prevalence of depression and anxiety was $13.2 \%$ and $5.3 \%$, respectively. The median score for dietary diversity was 6 [4-7]. We defined low dietary diversity as having a DDS score of less than 5 , and $45.1 \%$ of 
Table 1 Descriptive characteristics, dietary diversity score, depression and anxiety of participants

\begin{tabular}{|c|c|c|c|}
\hline Characteristics & Total $(n=288)$ & Centenarians $(n=38)$ & Offspring and spouse $(n=250)$ \\
\hline BMI (mean, SD) & $24.37 \pm 3.9$ & $20.93 \pm 3.65$ & $24.89 \pm 3.64$ \\
\hline Female (n, \%) & $152(52.8)$ & $31(81.6)$ & $121(48.4)$ \\
\hline \multicolumn{4}{|l|}{ Place of residence $(n, \%)$} \\
\hline Rural & $231(80.2)$ & $31(81.6)$ & $200(80.0)$ \\
\hline \multicolumn{4}{|l|}{ Degree of education (n, \%) } \\
\hline$\leq 9$ years & $253(87.8)$ & 37 (97.4) & $216(86.4)$ \\
\hline$>9$ years & $35(12.2)$ & $1(2.6)$ & $34(13.6)$ \\
\hline Spinsterhood/widowed & $70(24.3)$ & $37(97.4)$ & $33(13.2)$ \\
\hline \multicolumn{4}{|l|}{ Employment status (n, \%) } \\
\hline Paid work (part-time or full time) & $114(39.6)$ & $5(13.2)$ & $109(43.6)$ \\
\hline Farmer/homemaker & $174(60.4)$ & $33(86.8)$ & $141(56.4)$ \\
\hline \multicolumn{4}{|l|}{ Enough money to live on (n, \%) } \\
\hline Yes & $242(84.0)$ & $35(92.1)$ & 207 (82.8) \\
\hline No & $46(16.0)$ & $3(7.9)$ & $43(17.2)$ \\
\hline \multicolumn{4}{|l|}{ Smoking (n, \%) } \\
\hline Stroke (n, \%) & $28(9.7)$ & $1(2.6)$ & $27(10.8)$ \\
\hline Hypertension (n, \%) & $107(37.2)$ & $7(18.4)$ & $100(40.0)$ \\
\hline Diabetes (n, \%) & $23(8.0)$ & $2(5.3)$ & $21(8.4)$ \\
\hline Physical exercise (n, \%) & $111(38.5)$ & $9(23.7)$ & $102(40.8)$ \\
\hline BI (median, IQR) & $100[100-100]$ & 90 [80-96.25] & $100[100-100]$ \\
\hline \multicolumn{4}{|l|}{ Bl classification (n, \%) } \\
\hline Independent & $242(84.0)$ & $9(23.7)$ & $233(93.2)$ \\
\hline Dependent & $46(16.0)$ & $29(76.3)$ & $17(6.8)$ \\
\hline GAD-7 (median, IQR) & $0[0-2]$ & $0[0-0]$ & $1[0-2]$ \\
\hline Anxiety (n, \%) & $25(8.7)$ & $2(5.3)$ & $23(9.2)$ \\
\hline GDS-15 (median, IQR) & $2[1-3]$ & $2[1-3]$ & $3[1-3]$ \\
\hline
\end{tabular}

Table 1 (continued) 
Table 1 (continued)

\begin{tabular}{lccc}
\hline Characteristics & Total $(\mathrm{n}=288)$ & Centenarians $(\mathrm{n}=38)$ & Offspring and spouse $(\mathrm{n}=250)$ \\
\hline Depression (n, \%) & $37(12.8)$ & $5(13.2)$ & $32(12.8)$ \\
DDS (median, IQR) & $6[4-7]$ & $6[5-7]$ & $6[4-7]$ \\
DDS level (n, \%) & & & $15(39.5)$ \\
Low DDS & $130(45.1)$ & $23(60.5)$ & $115(46.0)$ \\
High DDS & $158(54.9)$ & $135(54.0)$ \\
\hline
\end{tabular}

IQR, interquartile range; BMI, body mass index; SD, standard deviation; BI, Barthel Index; GAD-7, the Generalized Anxiety Disorder Scale; GDS-15, the 15-item version of the Geriatric Depression Scale; DDS, dietary diversity score.

the older adults were classified as low dietary diversity.

\section{Association of general characteristics of study participants with depression and anxiety status}

As shown in Table 2, through comparing the differences between people with or without depression/anxiety, we found that people with depression or anxiety symptoms were more likely to have a low DDS. Moreover, people with a lower DDS had higher rates of anxiety and depression (Table 3). People with depression were more likely to live in rural areas, with insufficient daily living expenses and low frequency of physical exercise $(\mathrm{P}<0.05)$. In addition, those who never drank and did not have enough money to live on showed more anxiety $(\mathrm{P}<0.05)$. However, age, $\mathrm{BMI}$, gender, educational level, marital status, employment status, smoking, BI score, stroke, hypertension, and diabetes were not associated with depression or anxiety $(\mathrm{P}>0.05)$.

\section{Depression scores were negatively correlated with DDS}

Correlation analysis after adjusting variables found that DDS was negatively correlated with depression score among all 288 older adults $(\mathrm{r}=-0.224 ; \mathrm{P}<0.001)$. DDS scores of offspring and spouses were also negatively correlated with depression scores $(\mathrm{r}=-0.275 ; \mathrm{P}<0.001)$, but this correlation was not found in the centenarian group. No correlation was found between DDS and anxiety scores (Table 4).

\section{Higher dietary diversity as a protective factor against depression among elderly}

We conducted binary logistic regression, taking each of depression and anxiety as dependent variables (Table 5). DDS level was directly incorporated into the regression equation as an independent variable, and the crude OR value was obtained, which indicated that low DDS was a risk factor for depression (OR: 3.341 ; 95\% CI: 1.58 17.061; $\mathrm{P}=0.002)$. After adjustments were made for age, place of residence, sufficient income for daily living, and alcohol intake, we found that low DDS had a higher risk of depression than did high DDS (OR: 2.237; 95\% CI: 1.009-4.959; $\mathrm{P}=0.048$ ). However, regression analysis found no evidence for a predictive utility of dietary diversity for anxiety.

\section{Effects of various dietary components on anxiety and depression}

The comparison of consumption of various dietary components showed that group those with depression ingested fewer fish, eggs, meat, nuts, and legumes and their products than did people without depression; meanwhile, those with anxiety ingested fewer meat and nuts than those without anxiety (Figure S1). In the multivariate logistic regression models that were controlled for demographic characteristics, we found that consumption of legumes (OR: 0.415; 95\% CI: 0.188-0.920; $\mathrm{P}=0.030$ ) and nuts (OR: 0.255; 95\% CI: 0.116-0.561; $\mathrm{P}=0.001)$ at least once a week was a protective factor for depression, while consumption of nuts (OR: 0.405; 95\% CI: 0.168-0.978; $\mathrm{P}=0.044)$ and meat (OR: $0.396,95 \%$ CI: $0.161-0.975$; $\mathrm{P}=0.044)$ at least once a week was a protective factor for anxiety (Tables 6,7).

\section{Discussion}

Our study found that the incidence of anxiety and depression among the older adults living in the longevity area of Rugao was relatively low, whether in centenarians or their offspring and spouses. The overall prevalence of depressive 
Table 2 Comparison of basic data and dietary diversity score with anxiety or depression in older adults

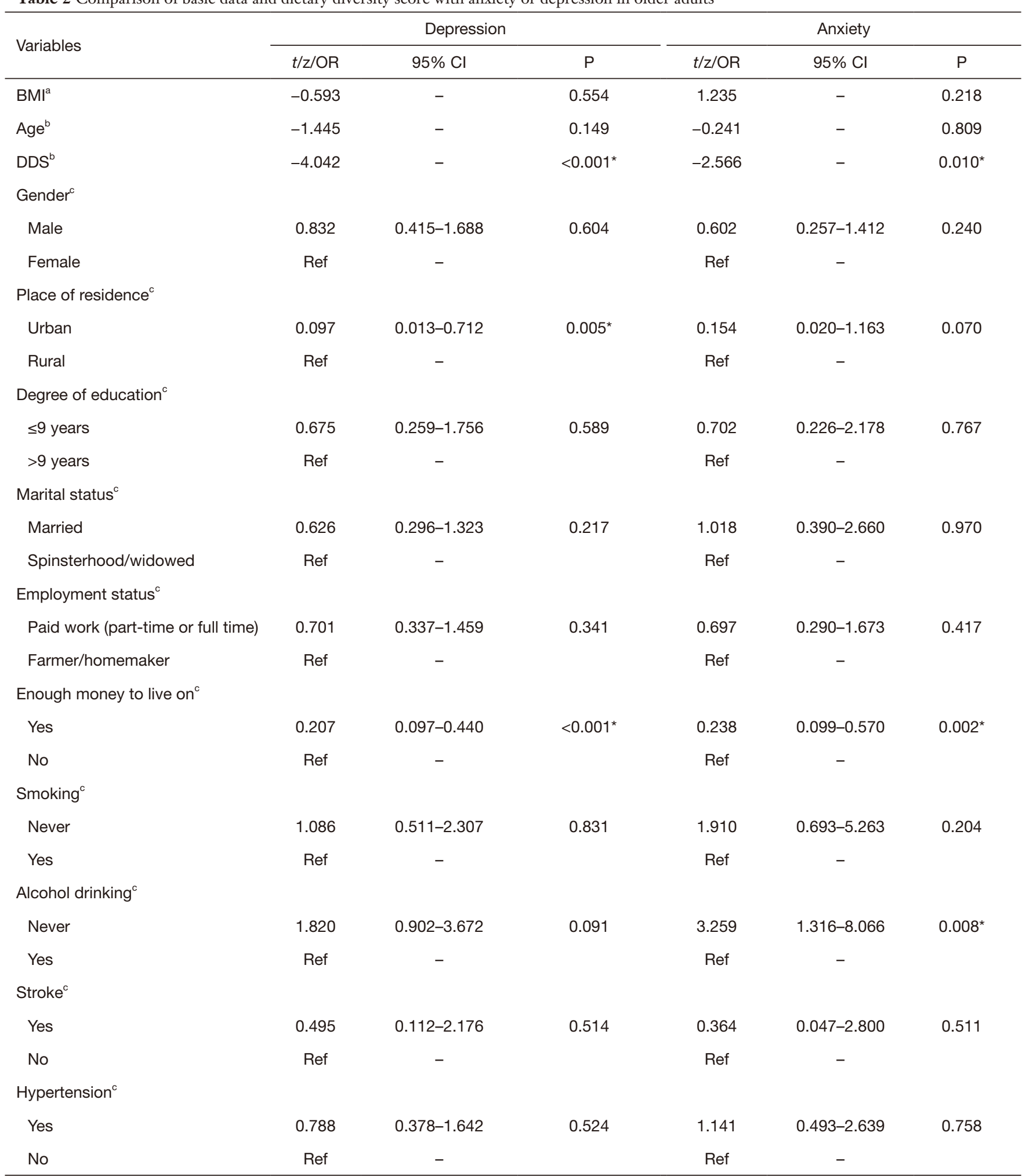

Table 2 (continued) 
Table 2 (continued)

\begin{tabular}{|c|c|c|c|c|c|c|}
\hline Variables & \multicolumn{3}{|c|}{ Depression } & \multicolumn{3}{|c|}{ Anxiety } \\
\hline \multicolumn{7}{|l|}{ Diabetes $^{c}$} \\
\hline Yes & 1.019 & $0.287-3.614$ & $>0.999$ & 1.002 & $0.221-4.546$ & $>0.999$ \\
\hline No & Ref & - & & Ref & - & \\
\hline Never & 3.716 & $1.497-9.226$ & $0.003^{*}$ & 1.682 & $0.679-4.167$ & 0.257 \\
\hline Yes & Ref & - & & Ref & - & \\
\hline \multicolumn{7}{|l|}{$\mathrm{Bl}^{\mathrm{c}}$} \\
\hline Independent & 0.647 & $0.275-1.521$ & 0.315 & 0.568 & $0.214-1.510$ & 0.389 \\
\hline
\end{tabular}

${ }^{\mathrm{a}}$, $t$-test; ${ }^{\mathrm{b}}$, Mann-Whitney $\mathrm{U} ;{ }^{\mathrm{c}}$, chi-square test. ${ }^{*}, \mathrm{P}<0.05$. OR, odds ratio; Cl, confidence interval; BMI, body mass index; DDS, dietary diversity score; BI, Barthel Index; Ref, reference.

Table 3 Influence of low or high DDS on anxiety and depression in the elderly

\begin{tabular}{lccc}
\hline Variables & Low DDS, n (\%) & High DDS, n (\%) & P \\
\hline Depression & & & $0.001^{*}$ \\
Yes & $26(20.0)$ & $11(7.0)$ & \\
No & $104(80.0)$ & $147(93.0)$ & \\
Anxiety & & & $0.047^{*}$ \\
Yes & $16(12.3)$ & $9(5.7)$ & \\
No & $114(87.7)$ & $149(94.3)$ & \\
\hline
\end{tabular}

*, $\mathrm{P}<0.05$. DDS, dietary diversity score.

Table 4 Correlation between the scores of dietary diversity, depression and anxiety in different age groups

\begin{tabular}{lcccccc}
\hline \multirow{2}{*}{ Groups } & \multicolumn{2}{c}{ Depression score ${ }^{\mathrm{a}}$} & & \multicolumn{2}{c}{ Anxiety score $^{\mathrm{b}}$} \\
\cline { 2 - 3 } \cline { 5 - 6 } & $\mathrm{r}$ & $\mathrm{P}$ & & $\mathrm{r}$ & $\mathrm{P}$ \\
\hline Total & -0.224 & $<0.001^{*}$ & & -0.082 & 0.165 \\
Centenarians & 0.138 & 0.430 & & 0.077 & 0.657 \\
Offspring and spouses & -0.275 & $<0.001^{*}$ & & -0.098 & 0.124 \\
\hline
\end{tabular}

a, adjusted for place of residence, enough money to use, and physical exercise; ${ }^{b}$, adjusted for enough money to use and alcohol drinking. * $\mathrm{P}<0.05$. symptoms in older adults in other countries ranges from $8 \%$ to $16 \%$ (31). A previous cross-sectional study surveyed 29 cities (urban areas only) in China and found that more than 39\% of older adults report symptoms of depression (32). Another study of older Asian immigrants living in New York found that $35 \%$ thought they were anxious and considered it a serious problem (33). The differences in the incidence of anxiety and depression reported in China versus other countries were likely due to the differences in the assessment tool and judgment criteria. As depression and anxiety can aggravate the quality of life, burden the health care system, and increase the risk of death (34), it is necessary to ameliorate the mental problems of older adults. Current treatments, such as medication and psychotherapy, are efficacious in only half of the afflicted individuals; however, the advent of nutritional psychiatry has provided evidence to be effective in some regards (35-37).

To our knowledge, this is the first study to examine the relationship between dietary diversity and the mental disorders of anxiety and depression in an older adult population, particularly those with extreme longevity. We found a negative correlation between DDS and depression among the older adults. This is consistent with some studies that suggest a link between diet and MH (38-40). However, 
Table 5 Association of DDS level with depression and anxiety

\begin{tabular}{|c|c|c|c|c|c|c|c|}
\hline Models & Factor & \multicolumn{3}{|c|}{ Depression state } & \multicolumn{3}{|c|}{ Anxiety state } \\
\hline \multirow[t]{3}{*}{ Model 1} & DDS level & & & & & & \\
\hline & Low & 3.341 & $1.581-7.061$ & $0.002^{*}$ & 2.324 & $0.991-5.449$ & 0.053 \\
\hline & High & Ref & - & & Ref & - & \\
\hline \multirow{2}{*}{ Model 2} & Low & 3.326 & $1.572-7.038$ & $0.002^{*}$ & 2.340 & $0.996-5.494$ & 0.051 \\
\hline & High & Ref & - & & Ref & - & \\
\hline \multirow[t]{2}{*}{ Model 3} & DDS level & & & & & & \\
\hline & Low & $2.237^{\mathrm{a}}$ & $1.009-4.959$ & $0.048^{*}$ & $1.558^{\mathrm{b}}$ & $0.635-3.819$ & 0.333 \\
\hline
\end{tabular}

Model 1, crude model; Model 2, adjusted by age; Model 3, ${ }^{\text {, }}$, adjusted by age, place of residence, enough money to use, alcohol drinking and physical exercise; ${ }^{b}$, adjusted by age, place of residence, enough money to use and alcohol drinking. ${ }^{*}, \mathrm{P}<0.05$. DDS, dietary diversity score; OR, odds ratio; $\mathrm{Cl}$, confidence interval; Ref, reference.

Table 6 Association between depression and nine food components included in DDS

\begin{tabular}{|c|c|c|c|c|c|}
\hline Factors & B & SE & $\mathrm{P}$ & OR & $95 \% \mathrm{Cl}$ \\
\hline Enough money to live & -1.402 & 0.418 & $0.001^{*}$ & 0.246 & $0.108-0.558$ \\
\hline Physical exercise & 0.845 & 0.494 & 0.087 & 2.329 & $0.884-6.134$ \\
\hline Legumes and their products & -0.878 & 0.406 & $0.030^{*}$ & 0.415 & $0.188-0.920$ \\
\hline Constant & -0.011 & 0.662 & 0.987 & 0.989 & \\
\hline
\end{tabular}

Adjusted by age, place of residence, enough money to life, alcohol drinking and physical exercise. *, $\mathrm{P}<0.05$. DDS, dietary diversity score; $\mathrm{SE}$, standard error; OR, odds ratio; $\mathrm{Cl}$, confidence interval.

Table 7 Association between anxiety and nine food components included in DDS

\begin{tabular}{|c|c|c|c|c|c|}
\hline Factors & $B$ & SE & $\mathrm{P}$ & OR & $95 \% \mathrm{Cl}$ \\
\hline Alcohol drinking & 1.007 & 0.485 & $0.038^{*}$ & 2.737 & $1.057-7.086$ \\
\hline Nuts & -0.903 & 0.449 & $0.044^{*}$ & 0.405 & $0.168-0.978$ \\
\hline Meat & -0.926 & 0.460 & $0.044^{*}$ & 0.396 & $0.161-0.975$ \\
\hline
\end{tabular}

Adjusted by age, place of residence, enough money to life and alcohol drinking. ${ }^{*}, \mathrm{P}<0.05$. DDS, dietary diversity score; SE, standard error; OR, odds ratio; $\mathrm{Cl}$, confidence interval. 
among centenarians, DDS was not significantly associated with anxiety and depression. Overall, the centenarians had lower anxiety and depression scores, and with only 38 participants in our study, we cannot rule out the possibility that this association exists. The regression analysis showed that people with low dietary diversity had a higher risk of depression, independent of age, place of residence, financial status, alcohol intake, and physical activity. A study in Iran found that DDS was inversely associated with anxiety among women (41). However, we did not find such association in our study. Future studies should examine the nuances of dietary in more detail and their links with anxiety, including dietary composition and cultural differences.

Evidence suggests that greater dietary variety is associated with better nutritional status in frail older adults (42). This age group is at a greater risk of nutritional deficiencies due to the effects of aging, acute and chronic diseases, and functional decline (43). In our study, the overall rating of dietary diversity of older adults was 6 [4-7], and there was no difference between the 2 age groups. Compared with the score reported in another study $(4.9 \pm 1.23)$, the dietary status of our study group was better (44). In addition, there is a strong link between longevity and nutritional status (45). Diverse diets have been shown to protect against chronic diseases such as cancers (46) and have been associated with a lower risk of mortality (19) and improved health status (47). Thus, we recommend increasing dietary diversity, especially among older adults, to maintain a healthy body in old age.

To consider the possibility that participants could have the same DDS but different dietary compositions, we incorporated the 9 foods that made up the DDS into the regression model. The findings suggest that regular intake of legumes, nuts, and meat could be considered protective factors, as eating legumes, nuts, or meat at least once a week was associated with a lower risk of anxiety or depression. The same conclusion was reached in a randomized controlled trial, in which an MED combined with nuts reduced the risk of depression in patients with type 2 diabetes (DM2) (48). A meta-analysis showed that several healthy foods, such as olive oil, fish, fruits, vegetables, nuts, legumes, poultry, dairy products, and unprocessed meat, were inversely associated with the risk of depression and were even thought to improve depressive symptoms (49). Unlike other studies, we did not find an association between vegetable and fruit consumption and anxiety and depression. Overall, $99.1 \%$ of our study subjects ate vegetables at least once a week, with only 3 oldest-old individuals reporting consumption of less than once a week. However, this may only be a local anomaly. In Rugao, people grow vegetables and fruits for themselves, and every family likely consumes them with high frequency. More prospective studies are needed to determine the effects of regular consumption of beans, nuts, and meat.

\section{Limitations}

A strength of our study is that it is the first of its kind to examine the relationship between dietary diversity and anxiety and depression in an older population, especially in centenarians who live incredibly long lives. However, some limitations to our study should be mentioned. The main limitation is the cross-sectional design which makes it impossible to determine the directionality of our findings. Depression or anxiety can have positive or negative effects on food intake $(50,51)$. Thus, we cannot discount the possibility of a reverse association in which depression and anxiety may interfere with dietary diversity (52). In addition, MH symptoms and diet were self-reported, and thus recall bias might have affected the validity of the findings. Finally, our study only surveyed one region, with a small number of centenarians, and our data should be compared with data from other parts of the country.

\section{Conclusions}

Our study suggested an association between low dietary diversity and high prevalence of anxiety and depression symptoms, although reverse causality and confounding factors cannot be ruled out as explanations. We recommend that people eat a wide variety of foods and increase dietary diversity. Since dietary intake is a controllable and modifiable risk factor, a more detailed understanding of the relationship between various diets and depression and anxiety may provide additional insights into how and when nutrition can be used to improve depression and anxiety. Further prospective studies are needed to provide evidence for optimal dietary intervention strategies.

\section{Acknowledgments}

We thank all the participants, the People's Government of Rugao, for supporting this study.

Funding: This research project has been supported by grants from the National Natural Science Foundation of China (grant No. 82071838), the Research Center of Gerontology 
and Longevity, the Affiliated Hospital of Nantong University (grant No. HS2018004), and Postgraduate Research \& Practice Innovation Program of Jiangsu Province (grant No. KYCX20_2846 and KYCX20_2848).

\section{Footnote}

Reporting Checklist: The authors have completed the STROBE reporting checklist. Available at https://apm. amegroups.com/article/view/10.21037/apm-21-1449/rc

Data Sharing Statement: Available at https://apm.amegroups. com/article/view/10.21037/apm-21-1449/dss

Peer Review File: Available at https://apm.amegroups.com/ article/view/10.21037/apm-21-1449/prf

Conflicts of Interest: All authors have completed the ICMJE uniform disclosure form (available at https://apm. amegroups.com/article/view/10.21037/apm-21-1449/coif). The authors have no conflict of interest to declare.

Ethical Statement: The authors are accountable for all aspects of the work in ensuring that questions related to the accuracy or integrity of any part of the work are appropriately investigated and resolved. The study was conducted in accordance with the Declaration of Helsinki (as revised in 2013). The study protocol and the consent form were approved by the Ethics Committee of The Affiliated Hospital of Nantong University and written informed consent was obtained from all participants. The Clinical Trial Registration number for this study is 2019-K045.

Open Access Statement: This is an Open Access article distributed in accordance with the Creative Commons Attribution-NonCommercial-NoDerivs 4.0 International License (CC BY-NC-ND 4.0), which permits the noncommercial replication and distribution of the article with the strict proviso that no changes or edits are made and the original work is properly cited (including links to both the formal publication through the relevant DOI and the license). See: https://creativecommons.org/licenses/by-nc-nd/4.0/.

\section{References}

1. Cheng X, Yang Y, Schwebel DC, et al. Population ageing and mortality during 1990-2017: A global decomposition analysis. PLoS Med 2020;17:e1003138.
2. Joyce J, Herbison GP. Reiki for depression and anxiety. Cochrane Database Syst Rev 2015;(4):CD006833.

3. World Health Organization. The global burden of disease: 2004 update. the Harvard School of Public Health on behalf of the World Health Organization and the World Bank; 2008.

4. Malhi GS, Mann JJ. Depression. Lancet 2018;392:2299-312.

5. Bakkane Bendixen A, Engedal K, Selbæk G, et al. Anxiety Symptoms in Older Adults with Depression Are Associated with Suicidality. Dement Geriatr Cogn Disord 2018;45:180-9.

6. Wilkinson P, Ruane C, Tempest K. Depression in older adults. BMJ 2018;363:k4922.

7. Riga S, Riga D, Mihailescu A, et al. Longevity health sciences and mental health as future medicine. Ann N Y Acad Sci 2010;1197:184-7.

8. Cheng A, Leung Y, Harrison F, et al. The prevalence and predictors of anxiety and depression in near-centenarians and centenarians: a systematic review. Int Psychogeriatr 2019;31:1539-58.

9. Fang EF, Scheibye-Knudsen M, Jahn HJ, et al. A research agenda for aging in China in the 21st century. Ageing Res Rev 2015;24:197-205.

10. Jesus M, Silva T, Cagigal C, et al. Dietary Patterns: A New Therapeutic Approach for Depression? Curr Pharm Biotechnol 2019;20:123-9.

11. Lai JS, Hiles S, Bisquera A, et al. A systematic review and meta-analysis of dietary patterns and depression in community-dwelling adults. Am J Clin Nutr 2014;99:181-97.

12. Li Y, Lv MR, Wei YJ, et al. Dietary patterns and depression risk: A meta-analysis. Psychiatry Res 2017;253:373-82.

13. Shen YC, Chang CE, Lin MN, et al. Vegetarian Diet Is Associated with Lower Risk of Depression in Taiwan. Nutrients 2021;13:1059.

14. Jacka FN. Nutritional Psychiatry: Where to Next? EBioMedicine 2017;17:24-9.

15. Zhang J, Zhao A. Dietary Diversity and Healthy Aging: A Prospective Study. Nutrients 2021;13:1787.

16. Preparation and use of food-based dietary guidelines. Report of a joint FAO/WHO consultation. FAO/WHO. World Health Organ Tech Rep Ser 1998;880:i-vi, 1-108.

17. Azadbakht L, Esmaillzadeh A. Dietary diversity score is related to obesity and abdominal adiposity among Iranian female youth. Public Health Nutr 2011;14:62-9.

18. Oldewage-Theron WH, Kruger R. Food variety and dietary diversity as indicators of the dietary adequacy and 
health status of an elderly population in Sharpeville, South Africa. J Nutr Elder 2008;27:101-33.

19. Liu CK, Huang YC, Lo YC, et al. Dietary diversity offsets the adverse mortality risk among older indigenous Taiwanese. Asia Pac J Clin Nutr 2019;28:593-600.

20. Owen L, Corfe B. The role of diet and nutrition on mental health and wellbeing. Proc Nutr Soc 2017;76:425-6.

21. Huang Y, Mark Jacquez G. Identification of a Blue Zone in a Typical Chinese Longevity Region. Int J Environ Res Public Health 2017;14:571.

22. Cai J, Chen S, Yu G, et al. Comparations of major and trace elements in soil, water and residents' hair between longevity and non-longevity areas in Bama, China. Int J Environ Health Res 2021;31:581-94.

23. Arsenault JE, Yakes EA, Islam MM, et al. Very low adequacy of micronutrient intakes by young children and women in rural Bangladesh is primarily explained by low food intake and limited diversity. J Nutr 2013;143:197-203.

24. Yin Z, Fei Z, Qiu C, et al. Dietary Diversity and Cognitive Function among Elderly People: A Population-Based Study. J Nutr Health Aging 2017;21:1089-94.

25. Spitzer RL, Kroenke K, Williams JB, et al. A brief measure for assessing generalized anxiety disorder: the GAD-7. Arch Intern Med 2006;166:1092-7.

26. Hinz A, Klein AM, Brähler E, et al. Psychometric evaluation of the Generalized Anxiety Disorder Screener GAD-7, based on a large German general population sample. J Affect Disord 2017;210:338-44.

27. Yesavage JA, Brink TL, Rose TL, et al. Development and validation of a geriatric depression screening scale: a preliminary report. J Psychiatr Res 1982-1983;17:37-49.

28. de Craen AJ, Heeren TJ, Gussekloo J. Accuracy of the 15item geriatric depression scale (GDS-15) in a community sample of the oldest old. Int J Geriatr Psychiatry 2003;18:63-6.

29. Lim PP, Ng LL, Chiam PC, et al. Validation and comparison of three brief depression scales in an elderly Chinese population. Int J Geriatr Psychiatry 2000;15:824-30.

30. O'Connell J, Henman MC, Burke É, et al. Association of Drug Burden Index with grip strength, timed up and go and Barthel index activities of daily living in older adults with intellectual disabilities: an observational crosssectional study. BMC Geriatr 2019;19:173.

31. Blazer DG. Depression in late life: review and commentary. J Gerontol A Biol Sci Med Sci 2003;58:249-65.

32. Yu J, Li J, Cuijpers P, et al. Prevalence and correlates of depressive symptoms in Chinese older adults: a populationbased study. Int J Geriatr Psychiatry 2012;27:305-12.

33. Löwe B, Decker O, Müller S, et al. Validation and standardization of the Generalized Anxiety Disorder Screener (GAD-7) in the general population. Med Care 2008;46:266-74.

34. Simning A, Fox ML, Barnett SL, et al. Depressive and Anxiety Symptoms in Older Adults With Auditory, Vision, and Dual Sensory Impairment. J Aging Health 2019;31:1353-75.

35. Moncrieff J. Misrepresenting harms in antidepressant trials. BMJ 2016;352:i217.

36. Richards DA, Ekers D, McMillan D, et al. Cost and Outcome of Behavioural Activation versus Cognitive Behavioural Therapy for Depression (COBRA): a randomised, controlled, non-inferiority trial. Lancet 2016;388:871-80.

37. Kok RM, Reynolds CF 3rd. Management of Depression in Older Adults: A Review. JAMA 2017;317:2114-22.

38. Kimura Y, Wada T, Okumiya K, et al. Eating alone among community-dwelling Japanese elderly: association with depression and food diversity. J Nutr Health Aging 2012;16:728-31.

39. Poorrezaeian M, Siassi F, Milajerdi A, et al. Depression is related to dietary diversity score in women: a crosssectional study from a developing country. Ann Gen Psychiatry 2017;16:39.

40. Jiang W, Mo M, Li M, et al. The relationship of dietary diversity score with depression and anxiety among prenatal and post-partum women. J Obstet Gynaecol Res 2018;44:1929-36.

41. Poorrezaeian M, Siassi F, Qorbani M, et al. Association of dietary diversity score with anxiety in women. Psychiatry Res 2015;230:622-7.

42. Bernstein MA, Tucker KL, Ryan ND, et al. Higher dietary variety is associated with better nutritional status in frail elderly people. J Am Diet Assoc 2002;102:1096-104.

43. Rivlin RS. Keeping the young-elderly healthy: is it too late to improve our health through nutrition? Am J Clin Nutr 2007;86:1572S-6S.

44. Gholizadeh F, Moludi J, Lotfi Yagin N, et al. The relation of Dietary diversity score and food insecurity to metabolic syndrome features and glucose level among pre-diabetes subjects. Prim Care Diabetes 2018;12:338-44.

45. Declercq D, Van Meerhaeghe S, Marchand S, et al. The nutritional status in CF: Being certain about the uncertainties. Clin Nutr ESPEN 2019;29:15-21.

46. McCullough ML, Feskanich D, Stampfer MJ, et al. Diet 
quality and major chronic disease risk in men and women: moving toward improved dietary guidance. Am J Clin Nutr 2002;76:1261-71.

47. Karimbeiki R, Pourmasoumi M, Feizi A, et al. Higher dietary diversity score is associated with obesity: a casecontrol study. Public Health 2018;157:127-34.

48. Sánchez-Villegas A, Martínez-González MA, Estruch R, et al. Mediterranean dietary pattern and depression: the PREDIMED randomized trial. BMC Med 2013;11:208.

49. Lang UE, Beglinger C, Schweinfurth N, et al.

Cite this article as: Li R, Zong ZY, Gu XX, Wang DN, Dong C, Sun C, Zhao R, Gu ZF, Gao JL. Higher dietary diversity as a protective factor against depression among older adults in China: a cross-sectional study. Ann Palliat Med 2022;11(4):12781289. doi: 10.21037/apm-21-1449
Nutritional aspects of depression. Cell Physiol Biochem 2015;37:1029-43.

50. Singh M. Mood, food, and obesity. Front Psychol 2014;5:925.

51. Kim S, Choe K, Lee K. Depression, Loneliness, Social Support, Activities of Daily Living, and Life Satisfaction in Older Adults at High-Risk of Dementia. Int J Environ Res Public Health 2020;17:9448.

52. Groesz LM, McCoy S, Carl J, et al. What is eating you? Stress and the drive to eat. Appetite 2012;58:717-21. 
Supplementary
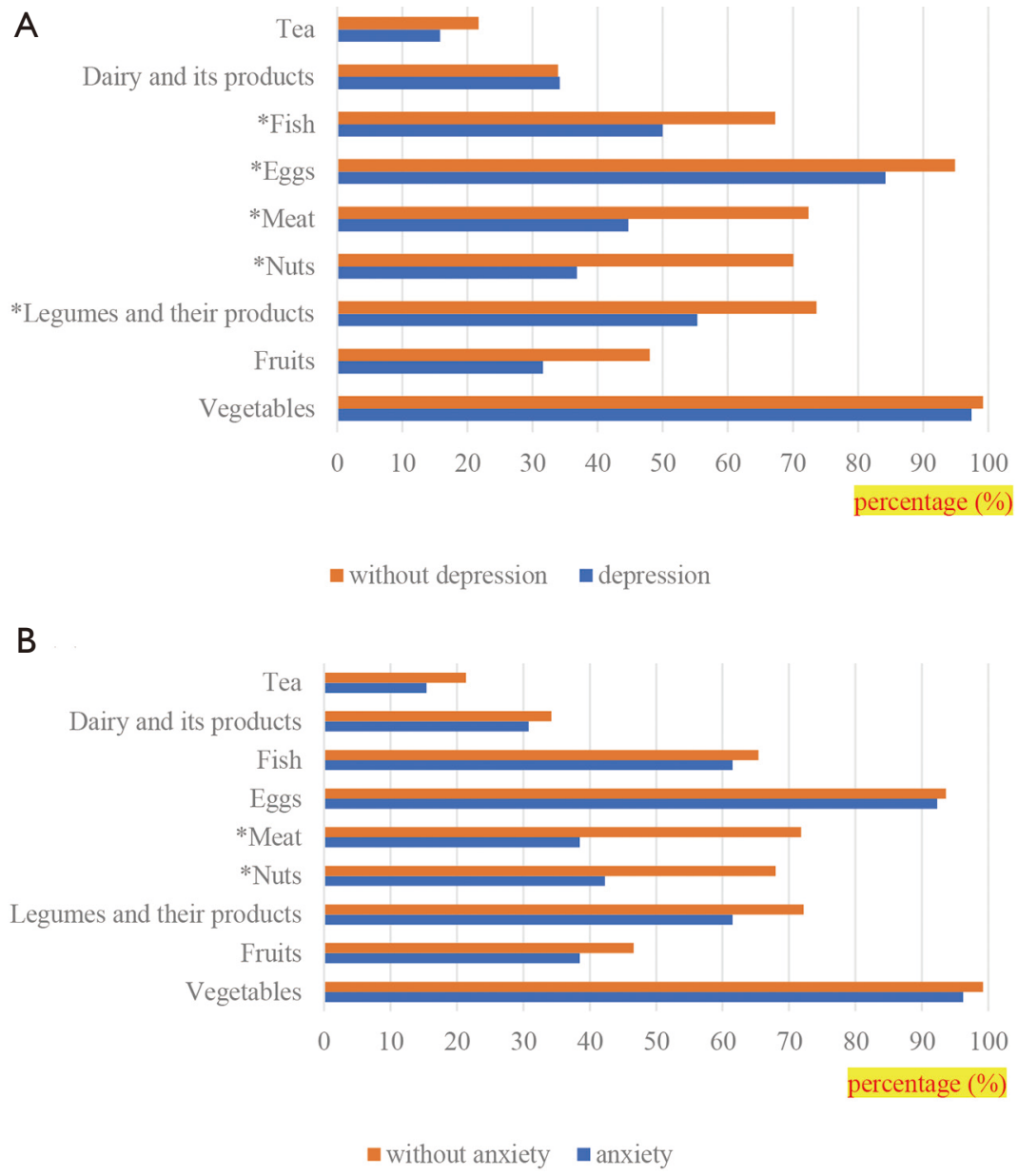

Figure S1 Food consumption across depressive (A) or anxious (B) status. Chi-square test was used to compare the each food intake in different mental states, with * indicating $\mathrm{P}<0.05$. The $\mathrm{X}$-axis was the percentage of people with or without depression/anxiety who eat specific food at least once a week. 